\title{
A vida à luz da ontologia fundamental e da metafísica da Vontade: uma aproximação hermenêutica
}

\section{Life in the light of fundamental ontology and the metaphysics of the Will: a hermeneutic approachment}

Dndo. Gabriel Henrique Dietrich dietrichgabriel@gmail.com Universidade Federal de Santa Maria

No período de sua obra que ficou conhecido como "década fenomenológica", Heidegger apresentou e desdobrou parcialmente o programa da ontologia fundamental, cujo centro de gravidade é a questão acerca do sentido do ser, canonicamente formulada em Ser e Tempo (1927). Dentre os desdobramentos parciais deste programa, destaca-se a tentativa de elucidação do sentido do ser da vida, empreendida no curso Os Conceitos Fundamentais da Metafísica: Mundo, Finitude e Solidão (1929). O objetivo principal deste trabalho é reconstruir em linhas gerais o programa da ontologia fundamental, especialmente em seu desdobramento na direção da elucidação do sentido do ser da vida. A partir dos elementos desta reconstrução será proposta uma breve aproximação hermenêutica com a interpretação da vida à luz da metafísica da Vontade, conforme desdobrada por Schopenhauer em $O$ mundo como vontade e como representação (1818).

PALAVRAS-CHAVE
Ontologia Fundamental. Metafísica da Vontade.

Vida. Aproximação Hermenêutica 
In the period of his work known as the "phenomenological decade," Heidegger presented and partially unfolded the program of fundamental ontology, whose center of gravity is the question about the sense of being, canonically formulated in Being and Time (1927). Among the partial developments of this program, we highlight the attempt to elucidate the meaning of the being of life, undertaken in the course The Fundamental Concepts of Metaphysics: World, Finitude and Solitude (1929). The main objective of this work is to reconstruct the program of the fundamental ontology, especially in its development in the direction of the elucidation of the meaning of the being of life. From the elements of this reconstruction a brief hermeneutical approach will be proposed with the interpretation of life in the light of the metaphysics of Will, as deployed by Schopenhauer in The World as Will and Representation (1818).

\section{KEYWORDS Fundamental Ontology. Metaphysics of the Will. Life. Hermeneutic Approachment}


A vida à luz da ontologia fundamental e da metafísica da Vontade: uma aproximação hermenêutica
Dndo. Gabriel Henrique

Dietrich [UFSM]

Uma formiguinha atravessa, em diagonal, a página ainda em branco. Mas ele, aquela noite, não escreveu nada. Pra quê? Se por ali havia passado o frêmito e o mistério da vida?

Quintana

\section{O programa da ontologia fundamental e a ontologia da vida: um breve delineamento geral}

É bastante conhecido que o pensamento de Heidegger sempre esteve às voltas com o problema do ser. No período de sua obra que ficou conhecido como a década fenomenológica (CROWELL, 1995), este problema é desdobrado em termos de um projeto ou de um programa de pesquisa: o programa da ontologia fundamental. Na medida em que se trata de um programa de pesquisa, a ontologia fundamental envolve um conjunto amplo e complexo de diferentes questões e tarefas que possuem uma unidade metodológica, dentre as quais se situam a pergunta pela essência da vida e a tarefa de elaborar uma hermenêutica ontológica da vida. Como esta pergunta e tarefa foram apresentadas e desdobradas no curso Os Conceitos Fundamentais da Metafisica: Mundo, Finitude e Solidão (1929), e como Ser e Tempo (1927) é anterior ao referido curso, é importante apresentar as linhas mestras que sustentam o programa da ontologia fundamental conforme elaboradas na magnus opus de Heidegger, já que algumas delas estão pressupostas em seu curso. De posse destas linhas mestras será possível reconstruir em termos gerais a ontologia da vida e a partir de aí elaborar a aproximação hermenêutica com a concepção da vida que pode ser lida à luz da metafísica da Vontade que consta em $O$ Mundo como Vontade e como Representação (1818). ${ }^{l}$ De que modo, então, o programa da ontologia fundamental é apresentado em Ser e Tempo?

1 Nesta reconstrução geral já será possível identificar importantes pontos de contato entre a ontologia fundamental e a metafísica da Vontade. Tendo em vista a sua relevância, tais pontos, como por exemplo o conceito de mundo e, no caso de Schopenhauer, o enraizamento do indívuo qua corpo no mundo, serão destacados mais de uma vez e ao longo do texto, inclusive antes mesmo da aproximação hermenêutica propriamente dita. Também é importante destacar que a referida aproximação aqui ensaiada toma por base textual principalmente o primeiro tomo de $O$ Mundo, e fica como tarefa a cumprir desdobrá-la mais sistematicamente considerando em profundidade o segundo tomo, bem como outros textos de Schopenhauer, como Da Vontade na Natureza. Adicionalmente, tendo em vista oferecer um quadro interpretativo mais amplo e inclusivo não restrito à década fenomenológica, seria preciso considerar também a avaliação crítica de Heidegger da recepção de Schopenhauer da filosofia transcendental clássica de Kant, apresentada em seus seminários sobe Nietzsche. Agradeço ao parecerista por este importante apontamento. 
A vida à luz da ontologia fundamental e da metafísica da Vontade: uma aproximação hermenêutica
Dndo. Gabriel Henrique

Dietrich [UFSM]

Do ponto de vista programático ou estrutural, a ontologia fundamental é apresentada como possuindo dois eixos principais de sustentação: 1. A analítica da existencialidade da existência e 2. A destruição da história da ontologia (HEIDEGGER, 2009, p. 59). Apenas o primeiro ponto foi elaborado sistematicamente por Heidegger em Ser e Tempo, mas antes de reconstruí-lo é importante caracterizar muito genericamente o segundo, pois esta caracterização se mostrará auxiliar adiante, uma vez que permite uma aproximação decisiva com Schopenhauer e que conduz ao problema da opacidade, mistério ou enigmaticidade constitutiva do modo de ser da vida, além de permitir suspender uma possível recepção crítica da metafísica da Vontade em termos de um compromisso com a metafísica da presença.

Por "destruição", Heidegger não tem em vista algo assim como um aniquilamento ou demolição da tradição de modo a obter a derrocada da metafísica ocidental. Trata-se de uma recepção interpretativa das concepções de ser legadas pela tradição. Mais especificamente, esta recepção procura destacar o vínculo implícito entre ser e tempo que opera, na maior parte das vezes inadvertidamente, em tais concepções. O resultado crítico desta recepção consiste no diagnóstico de uma restrição injustificada que identifica ser com presença, ou, dito em outros termos, que o identifica exclusivamente com um dos modos do tempo, a saber, o presente, e que serve de base comparativa para determinar o passado, como o não-mais-presente, e o futuro, como o ainda-não-presente. De aí a conhecida expressão "metafísica da presença", que consiste justamente no diagnóstico crítico de Heidegger em relação à tradição. ${ }^{2}$ Deixando de lado a miríade de problemas e consequências que esta interpretação eventualmente acarretaria, cabe destacar apenas que uma das dificuldades que a metafísica da presença enfrenta diz respeito justamente à sua inadequação interpretativa com relação ao modo de ser do ser humano, ou, para usar a conhecida expressão de Heidegger, do Dasein (ser-aí). Isso nos conduz ao primeiro eixo de sustentação mencionado anteriormente, a saber, a analítica da existencialidade da existência, na qual justamente o foco é mostrar e interpretar o ser do existente humano adequadamente.

2 Se este diagnóstico crítico inclui Schopenhauer, permanece uma questão em aberto que pode ser abordada a partir de diferentes linhas de resposta. Uma destas linhas de respostas imediata é a de que incluiria, sim, dado que a tese valeria, em princípio, para a tradição metafísica como um todo, da qual Schopenhauer, em algum sentido, certamente faz parte. Por outro lado, outra linha de resposta poderia ser a de que não inclui, uma vez que nominalmente são destacadas as concepções de ser de Aristóteles, Kant e Descartes. Ou seja, diante daquela questão em aberto é possível responder "sim e não". Seguindo Carman (1995), assumo que em relação às filosofias da physis é mais difícil de mostrar o compromisso com a metafísica da presença, e, adicionalmente, ao fim do artigo proponho que Schopenhauer seja interpretado, ao menos no que diz respeito à sua interpretação da vida, como pelo menos parcialmente desviante desta tradição. 
A vida à luz da ontologia fundamental e da metafísica da Vontade: uma aproximação hermenêutica
Dndo. Gabriel Henrique

Dietrich [UFSM]

É bastante conhecido que em Ser e Tempo o Dasein ou o existente humano é interpretado a partir de e em termos da estrutura do ser-no-mundo. De acordo com Heidegger, os hífens da expressão indicam que o que é por ela designado é uma totalidade articulada e unificada, divisível apenas para fins de análise, ou seja, apenas ao assumir-se uma postura teórica ou temática $(2009$, p. 76$)$. Não cabe aqui apresentar detalhadamente a análise tripartite do ser-no-mundo que destaca os momentos constitutivos a) do ser-em enquanto tal, b) do ser-com e c) da mundanidade do mundo, mas sim chamar atenção para o núcleo desta análise que toma como ponto de partida a familiaridade cotidiana com os entes intramundanos. É a partir de resultados obtidos por meio da fenomenologia da cotidianidade que será possível apresentar a tarefa de elaborar uma hermenêutica ontológica da vida e procurar a resposta para a pergunta por sua essência.

Na primeira divisão (do §12 ao §45) de Ser e Tempo Heidegger apresentou e desdobrou sua celebrada fenomenologia da familiaridade. Longe de caracterizar o existente humano como um sujeito abstrato que contempla o mundo como quem assiste, desinteressado, um espetáculo do qual não faz parte, a fenomenologia da familiaridade situa o existente humano em contextos prático-operativos no interior dos quais os entes se apresentam significativamente, com relevância e importância. Dito de outro modo, desde a perspectiva de Heidegger o existente humano não pode ser caracterizado inicialmente em termos de um sujeito contemplativo que se relaciona com objetos em termos de representações abstratas, mas como um agente que se encontra em meio ao mundo e aos entes que se apresentam a partir do mundo, entes que já estão imersos em significado e que possuem uma diversidade de identidades ontológicas.

Desta fenomenologia da familiaridade cotidiana com os entes resultam consequências ontologicamente importantes, pois os entes não-humanos que configuram o espaço de sentido no interior do qual o existente se move não podem ser todos adequadamente caracterizados como coisas ou objetos em sua acepção epistêmica, cujo modo de ser é o da subsistência (Vorhandenheit). Positivamente, este resultado pode ser apresentado inicialmente nos termos do reconhecimento de uma ontologia da disponibilidade (Zuhandenheit), isto é, a partir da cotidianidade é possível visualizar um sentido ou modo de ser que estrutura os entes não-humanos que se apresentam nestes contextos e que não pode ser descrito em termos de meras coisas, como à maneira de um materialismo ou fisicalismo clássicos.

Não cabe aqui extrair os detalhes deste resultado ontológico, mas apenas destacar que a partir dele é possível identificar em Heidegger o compromisso 
A vida à luz da ontologia fundamental e da metafísica da Vontade: uma aproximação hermenêutica
Dndo. Gabriel Henrique

Dietrich [UFSM]

ou o reconhecimento de que há vários sentidos ou modos de ser irredutíveis. De fato, na literatura especializada contemporânea, atribui-se a Heidegger a defesa de um pluralismo ontológico ou de modos de ser, isto é, o reconhecimento de que o conceito de ser não é unívoco e que, para remontar a Aristóteles, se diz de diferentes modos (McDANIEL, 2017). Dentre os diferentes modos de ser irredutíveis reconhecidos no programa da ontologia fundamental encontra-se o modo de ser da vida (Leben), que justamente será o foco reconstrutivo das páginas que se seguirão. Mas em que consiste, em linhas gerais, um modo de ser? O que se entende por esta expressão? E especificamente em relação ao modo de ser da vida, o que dizer?

Em linhas gerais, um modo de ser consiste em um conjunto de estipulações ontológicas que normatizam a maneira de algo 1. individuar-se, 2. fenomenalizar-se e 3. determinar-se (REIS, 2014, p. 33). Considerando ilustrativamente um modo de ser à luz do princípio de individuação, seria possível afirmar que cada modo de ser implica em uma relação qualificada e irredutível com o espaço e com o tempo. Por exemplo, desde a perspectiva da fenomenologia da cotidianidade não é adequado dizer de um ente disponível, por exemplo, um computador, que ele está no espaço da mesma maneira que um mero objeto material está, mas ele está no espaço de um modo qualificado. Os termos de arte de Heidegger para esta relação qualificada do ente utensiliar com o espaço são 'lugar próprio' (Platz) e 'zona' (Gegend): há um lugar próprio e um lugar impróprio para se deixar um computador (e também sua articulação em partes é muito especial: há um lugar adequado ou preferível para se deixar o mouse, o teclado e o monitor, por exemplo, e também no interior da casa, em que dificilmente se encontra um computador no banheiro) (HEIDEGGER, 2009, p. 125). Ou seja, entes cujo modo de ser é o da disponibilidade não são meros agregados de matéria com uma determinada extensão e que eventualmente podem constar em descrições físico-matemáticas nas quais são destacadas suas propriedades objetivas, mas são entes que possuem funções e estão inseridos em totalidades espacialmente qualificadas a partir das quais travam relações pragmáticas com outros entes disponíveis e a partir das quais chegam a ser os entes que são. É importante manter em vista estas características dos entes utensiliares na medida em que elas serão uma espécie de polo comparativo junto ao qual a vida será interpretada por Heidegger. ${ }^{3}$

3 Outro polo de comparação, tomado tanto em Ser e Tempo quanto no curso Os Problemas Fundamentais da Metafisica, é o modo de ser da subsistência (Vorhandenheit), que em linhas gerais diz respeito àqueles entes cuja identidade ontológica é descritível em termos de objeto em sua acepção epistêmica, ou, dito de modo mais genérico e não-epistêmico, de meras coisas. Desde a perspectiva de Heidegger, nem existentes humanos, nem entes vivos e nem entes 
A vida à luz da ontologia fundamental e da metafísica da Vontade: uma aproximação hermenêutica
Dndo. Gabriel Henrique

Dietrich [UFSM]

Como visto anteriormente, a existência humana é inicialmente elucidada tematicamente por meio de uma fenomenologia do modo cotidiano de ser-no-mundo. Em Ser e Tempo, Heidegger reserva para o termo "existência" uma acepção técnica de acordo com a qual é inadequado dizer, por exemplo, de um ente utensiliar, como um alicate, que ele existe. Sem dúvida este ente não é irreal e possui, sim, ser, mas o ponto é destacar o modo de ser deste ente. Adicionalmente, diz-se de números que eles são, mas que eles não existem, porquanto eles são consistentes (Bestand), que é modo próprio respectivo de ser dos entes abstratos. Mas e o que dizer em relação à vida? Tomando por base o que foi dito, não é adequado, dentro do marco conceitual estabelecido pelo programa da ontologia fundamental, dizer de entes vivos que eles existem, embora sem dúvida eles sejam algo. Mas então o que é isto- o vivo? De que modo e a partir de quais orientações conceituais e metodológicas seria possível determinar o vivo enquanto tal?

Na medida em que vida e existência são apresentadas por Heidegger como dois modos de ser distintos e irredutíveis, e na medida em que em Ser e Tempo a fenomenologia hermenêutica restringe-se a exibir e interpretar o modo de ser da existência, para a tarefa de elucidar o sentido do ser da vida é preciso passar para o curso Os Conceitos Fundamentais da Metafisica: mundo, finitude e solidão. É neste contexto em que a pergunta pela essência da vida é posta, e é a partir do modo como esta tematização se desdobra que procuraremos elaborar mais diretamente a aproximação hermenêutica com a metafísica da Vontade e o modo como a vida é desde aí interpretada por Schopenhauer.

O ponto de partida e a orientação da hermenêutica ontológica da vida são as três teses diretivas que estruturam seu desdobramento, a saber: 1. A tese de que a pedra é sem mundo, 2. A tese de que o animal é pobre de mundo e 3, a tese de que o existente humano é formador de mundo (HEIDEGGER, 2011, p. 228). A tese da pobreza de mundo é bastante controversa e complexa, mas de saída é importante considera-la como não-avaliativa, como não implicando uma consideração demeritória da vida. Positivamente, a pobreza de mundo diz respeito ao acesso indeterminado (desde a nossa perspectiva) que o animal tem em relação a algo, e traz à tona o que ficou conhecido como o problema da

utensiliares são adequadamente descritíveis em termos de meras coisas, e, até certo ponto, por razões análogas (REIS, 2014, p. 110). Dentre estas razões encontra-se o caráter relacional essencial de existentes humanos, de entes utensiliares e de entes vivos, e que falta ao modo de ser de entes subsistentes ou de meras coisas, que justamente são determinadas isoladamente e por propriedades auto-referidas. Adicionalmente, a relação espacial de entes utensiliares, vivos e existentes não é adequadamente descritível nos termos de uma relação espacial neutra ou homogênea que meras coisas possuem, mas deve ser entendida relativamente a cada modo de ser, isto é, trata-se de uma relação espacial qualificada, inteligível à luz de cada modo de ser. 
A vida à luz da ontologia fundamental e da metafísica da Vontade: uma aproximação hermenêutica
Dndo. Gabriel Henrique

Dietrich [UFSM]

transposição. Por exemplo, um cachorro ouve um barulho e muda sua postura: ele eriça seus pelos, começa a caminhar ao redor da casa, move-se por todo o terreno, para, ergue as orelhas e então continua, por vezes percorrendo diversas direções. Desde um ponto de vista fenomenológico, o que significa este comportamento do animal? Como seria possível determinar em relação a quê o animal se comporta? O problema da transposição diz respeito à dificuldade de nós, humanos, termos acesso direto àquilo que, metaforicamente dito, seria "a vida intencional" do animal: o em relação a quê seu comportamento se desdobra. Inicialmente, a tese da pobreza de mundo destaca justamente esse caráter indeterminado do comportamento do animal: por um lado ele se comporta em relação a algo, pois seu comportamento adquiriu contornos muito diferenciados em um determinado momento, mas por outro lado não nos é possível, ao menos de saída e imediatamente, determinar aquilo que disparou o comportamento, por exemplo, o eriçar o pelo do cachorro e a sua expedição pelo terreno.

Na medida em que a tarefa que Heidegger se coloca é a de determinar a vida em sua essência, e sua execução se dá por meio de uma hermenêutica ontológica, podemos nos perguntar: qual é, então, a essência da vida? De acordo com Heidegger, essencialmente a vida é organismo: ser vivo é ser organismo ( HEIDEGGER, 2011, p. 272). Obviamente, esta determinação da essência da vida nos coloca outras questões, pois agora justamente a tarefa é interpretar em que consiste isso que é um organismo. E é a partir desta interpretação que serão apresentadas as determinações dos entes qua entes vivos, e, portanto, que nos permitirão, posteriormente, uma breve aproximação com a metafísica da Vontade, especialmente em relação à interpretação da vida como discórdia, luta e conflito.

Organismos são totalidades que articulam unificadamente órgãos. O órgão é, por assim dizer, o elemento mínimo que configura o ente vivo, e que, portanto, determina o ser do vivo (HEIDEGGER, 2011, p 273). Assim como os utensílios, órgãos são caracterizados não por um fechamento e por estarem autocontidos à maneira de meras coisas, mas por terem funções a partir das quais são relacionados a algo: eles são para algo... ${ }^{4}$ Dito de outro modo: órgãos possuem funções e capacidades, como por exemplo o ouvido, que é para ouvir. Formalmente,

4 As reticências indicam dois elementos importantes: 1 . O traço formal que caracteriza a relação (qualquer utensílio, assim como qualquer órgão, está relacionado a algo de uma maneira determinada) e 2. Que em relação ao órgão determinar o relata de seu direcionamento implicaria em assumir já uma premissa metafisicamente discutível, a de que seria possível um acesso àquilo que se apresenta para o organismo. Mais genericamente, no jargão heideggeriano expressões como "estar dirigido para..." designam o movimento próprio da intencionalidade, que no caso da existência humana é positivamente qualificado como transcendência. Se e em que medida os animais transcendem e chegam a sair de si mesmos, é um tema bastante importante que logo a seguir será considerado a partir da relação entre perturbação, pulsão e aprisionamento do animal em seu círculo envoltório. 
A vida à luz da ontologia fundamental e da metafísica da Vontade: uma aproximação hermenêutica
Dndo. Gabriel Henrique

Dietrich [UFSM]

Heidegger distingue entre a função de um utensílio e a serventia de um órgão, e, embora esta distinção seja importante para os propósitos do programa da ontologia fundamental, neste contexto importa apenas destacar o caráter funcional ou serviente do órgão. Se um organismo é essencialmente uma totalidade de órgãos articulada unificadamente, então os organismos não são meras coisas prontas, acabadas e fechadas, mas estão sempre vinculados a outros entes, assim como os entes utensiliares e os existentes humanos (eles são entes determinados holisticamente em seu ser, isto é, sua identidade ontológica é relacional).

Em relação ao caráter de servir do órgão, Heidegger introduz uma distinção importante e contra-intuitiva com a noção de aptidão (Fähigheit). A inversão contra-intuitiva que Heidegger faz é a de que não é porque se tem um determinado órgão, por exemplo, o olho, que se tem a aptidão para ver, mas porque há a aptidão para ver é que há o respectivo órgão. Ou seja, a aptidão é anterior e a partir dela são formados órgãos. É neste sentido que o órgão, considerado a partir de sua dependência relativa a determinada aptidão, está a serviço de... Heidegger justifica esta tese observando infusórios e organelas que criam seus órgãos à medida que os utilizam, mas que após a utilização os modificam e descartam, a seguir criando outros órgãos aptos a outras possibilidades ${ }^{5}$ (McNEILL, 2006, p. 8). Deixando de lado o problema da adequação e da suficiência desta justificativa, por exemplo, se seria aceitável estender a tese para organismos muito mais complexos, como mamíferos, ela nos permite destacar algo importante: organismos criam órgãos à medida que são aptos e isso traz à tona uma compreensão do organismo em termos de uma unidade, além de permitir afirmar que propriamente não são os órgãos que têm aptidões ou são aptos, mas o próprio organismo. Nesse sentido se diz dos organismos que eles possuem aptidões, porquanto integram unificada e articuladamente órgãos formados a partir de funções relativas a aptidões determinadas. Na medida em que a identidade do ente vivo qua indivíduo não está restrita à sua unidade corpórea ou morfológica, sua unidade é apresentada conceitualmente por Heidegger em termos de círculo envoltório (Umring): entes vivos trazem consigo um espaço de possibilidades no interior do qual suas aptidões se desdobram, um círculo no interior do qual desdobram as suas possibilidades de ser (HEIDEGGER, 2011, p. 324).

5 Há uma importante recepção interpretativa da ontologia fundamental que destaca o caráter decisivo das noções modais para o estabelecimento e justificação dos diferentes modos de ser (REIS, 2014). Em Ser e Tempo, a existência humana é interpretada em termos de possibilidade, e Heidegger chega mesmo a afirmar que em relação à existência humana a possibilidade está acima da efetividade. Não é irrazoável pensar, portanto, que em relação à vida também há o reconhecimento de que a possibilidade é uma determinação modal mais fundamental do que a efetividade ou necessidade, o que abriria uma linha de justificação para a tese da anterioridade da aptidão em relação ao órgão. 
Até aqui, temos que o ser vivo consiste em uma unidade orgânica que é constituída pelo ser-apto do órgão e que implica em um círculo envoltório no interior do qual as aptidões se desdobram. A qualificação do espaço de possibilidades no interior do qual o ente vivo chega a ser o ente que ele mesmo é permite apresentar a perturbação (Benommenheit), a pulsão ou movimento pulsional (Scneetreiben) e o aprisionamento (Eigenommen), que também são determinações constitutivas dos animais. Em linhas gerais, a perturbação diz respeito ao comportamento do animal, que é, por assim dizer, disparado a partir do modo como algo entra em seu círculo envoltório. Mais especificamente, o que é disparado nesta perturbação são as pulsões do animal que estão na base do seu comportar-se em relação a.., ou, dito com a terminologia própria aos entes vivos, em seu ser-perturbado-por...Por fim, na medida em que a própria noção de circularidade traz à tona uma sugestão de fechamento, há a sugestão de um aprisionamento do animal em seu próprio círculo envoltório ou ambiental e junto-a-quê se dá no interior deste círculo. O aprisionamento diz respeito ao modo como se desdobram as pulsões no animal, de modo que ele sempre está, de algum modo, enredado em seu próprio círculo desinibitório e atrelado às suas aptidões em perturbações determinadas vinculadas a algo.

Para resumir, então, a hermenêutica ontológica da vida, podemos afirmar que os entes vivos são considerados por Heidegger como possuindo um modo de ser próprio e irredutível, não descritível em termos de meras coisas ou até mesmo primordialmente em termos de objetos (como possuindo propriedades objetivas à maneira das propriedades de uma coisa). Em termos positivos, inicialmente o ente vivo é interpretado à luz do conceito de organismo, que designa o modo de ser dos entes vivos. Partindo do conceito de organismo e destacando sua estrutura interna, são destacadas articuladamente outras determinações estruturais do modo de ser da vida: a relação inversa de pertinência aptidão/órgão, a perturbação como comportamento do animal, a pulsão e o aprisionamento, e o círculo ambiental ou envoltório no interior do qual algo se apresenta para o animal e que ele, por assim dizer, carrega sempre junto de si.

Por fim, cabe destacar dois pontos importantes: 1. A hermenêutica ontológica da vida, conforme elaborada por Heidegger, restringe-se a uma interpretação dos entes vivos qua animais, embora nem todo ente vivo seja um animal, e isso deixa em aberto em que medida e até que ponto a caracterização da vida qua animal também se estende para a vida vegetativa; 2 . Entendidos como círculos envoltórios aprisionados em pulsões, os animais relacionam-se em si e com seu ambiente em termos de luta: há uma luta para manter seu próprio círculo (HEIDEGGER, 2011, p. 356). Os dois pontos serão importantes para elaborarmos a 
A vida à luz da ontologia fundamental e da metafísica da Vontade: uma aproximação hermenêutica
Dndo. Gabriel Henrique

Dietrich [UFSM]

aproximação hermenêutica com a metafísica de Schopenhauer, pois vista sob a luz da metafísica da Vontade a vida se apresenta como luta e conflito perpétuos, mas ela não está restrita aos animais, pois a interpretação de Schopenhauer é mais ampla e inclusiva, porquanto se estende também para a vida vegetativa, e não apenas para a vida animal. É para a metafísica da Vontade que nos voltaremos agora, e procuraremos ensaiar uma breve aproximação hermenêutica.

\section{A aproximação hermenêutica: a vida à luz da metafísica da Vontade e da hermenêutica ontológica da vida}

Apesar de ambos pertencerem à tradição filosófica alemã pós-kantiana e que se insere em campos de disputas metafísicas que estão relativamente próximos, Arthur Schopenhauer e Martin Heidegger não são exatamente dois autores que a recepção crítica procura vincular, mesmo que ambos mantenham proximidade com a filosofia transcendental de Kant. Esta ausência de aproximação é identificada inclusive na atitude de Heidegger em relação a Schopenahuer. Naturalmente, esta ausência de aproximação levanta questões importantes, uma vez que certamente Heidegger leu O Mundo como Vontade e como Representação, apesar de que em suas principais obras pouquíssimo ou nada seja dito sobre esta obra. Qual seria a razão para esta lacuna hermenêutica? De que maneira poderíamos tentar contorna-la, ou, ao menos, diminuir sua extensão e profundidade?

No que diz respeito à primeira pergunta, não parece haver uma resposta simples ou direta. Além disso, uma vez que o programa da ontologia fundamental colocou para si a tarefa de perguntar pela essência da vida, e uma vez que a vida figura centralmente no interior da metafísica da Vontade, pois, como lemos no quarto capítulo de $O$ Mundo, dizer da Vontade que ela é Vontade de vida seria um pleonasmo, a ausência de resposta mostra-se ainda mais instigante. Deixando de lado as possíveis respostas para esta indagação, mas mantendo presente a inquietação à qual ela nos conduz, cabe aqui apenas mencionar que há uma aproximação importante entre Schopenhauer e Heidegger feita por Rudolf Malter (1976). ${ }^{6}$ Esta aproximação é mencionada aqui com o intuito de,

6 Como desdobramento parcial da destruição da história da ontologia é possível destacar os textos de Heidegger Kant e o Problema da Metafísica e Interpretação Fenomenológica da Crítica da Razão Pura, ambos pertencentes ao período imediatamente posterior à publicação de Ser e Tempo. De acordo com a resenha crítica de Günter Zöller (1995), em seu livro Malter propõe uma interpretação da metafísica da Vontade que a considera como próxima aos desdobramentos que a filosofia transcendental sofreu de Kant até Heidegger, o que significaria ler Schopenhauer como antecipando alguns desdobramentos tardios. O título desta resenha é justamente 
A vida à luz da ontologia fundamental e da metafísica da Vontade: uma aproximação hermenêutica
Dndo. Gabriel Henrique

Dietrich [UFSM]

por um lado, reconhecer que algo assim como o que se ensaia aqui já foi feito por um importante estudioso da filosofia alemã, mas, sobretudo, porque ela sinaliza para a possibilidade de restringir ou contornar a lacuna que há entre os dois autores, demonstrando, adicionalmente, que não há um impedimento de princípio. Longe de tentar esgotar as possíveis variações aproximativas, o que se ensaiará a seguir é apenas uma tentativa de, por um lado, aproximar dois importantes autores tomando como ponto de aproximação o modo como a vida é por eles interpretada, e, por outro lado, procurar, por meio dessa aproximação mesma, qualificar cada uma das interpretações. De que maneira, portanto, a vida é interpretada à luz da metafísica da Vontade? E de que modo esta interpretação articula-se com a hermenêutica ontológica da vida e seus resultados parciais $^{7}$ anteriormente apresentados?

Uma maneira de iniciar a articular uma linha de resposta para a primeira pergunta é considerar a seguinte passagem, extraída do $\$ 23$ do segundo tomo de $O$ Mundo como Vontade e como Representação, na qual lemos que:

De fato, a fronteira entre o orgânico e o inorgânico é a mais rigorosamente estabelecida em toda a natureza e talvez a única que não admite transição; de modo que 'natura non facit saltus' parece sofrer aqui uma exceção. Ainda que muitas cristalizações mostrem semelhança externa com uma figura vegetal, existe ainda uma diferença fundamental e essencial entre o mais diminuto líquen, o mais humilde bolor e o inorgânico.

Nesta passagem identificamos o reconhecimento de Schopenhauer de que há um abismo entre o orgânico e o inorgânico, e que por mais que haja semelhanças entre os dois âmbitos, há ainda entre ambos uma diferença fundamental. Considerando a apresentação anterior dos diversos modos de ser reconhecidos

\footnotetext{
Schopenhauer e o Problema da Metafísica, o que sugere que há um campo em aberto possível para uma aproximação hermenêutica mais sistemática entre Heidegger e Schopenhauer, uma que esteja alinhada com a interpretação heideggeriana de Kant e que poderia resultar em uma interpretação fenomenológica de $O$ Mundo como Vontade e como Representação.

7 É importante ressaltar que os resultados aos quais a hermenêutica ontológica da vida chega são objeto de uma profunda autocrítica de Heidegger, pois eles seriam severamente restringidos em razão de impedimentos metodológicos básicos. Este é outro ponto que permanece em aberto para eventuais desdobramentos, pois na medida em que a autocrítica de Heidegger afeta os resultados de sua hermenêutica ontológica da vida, não é irrazoável pensar que ela afetaria, também, uma aproximação hermenêutica que toma como um dos polos aproximativos tais resultados.
} 
A vida à luz da ontologia fundamental e da metafísica da Vontade: uma aproximação hermenêutica
Dndo. Gabriel Henrique

Dietrich [UFSM]

por Heidegger, esta passagem poderia ser lida como sinalizando um reconhecimento de ao menos dois modos irredutíveis de ser: o modo de ser orgânico e o modo de ser inorgânico. ${ }^{8}$ Deixando de lado por enquanto o problema do inorgânico, que tipo de elucidação interpretativa do líquen e do mais diminuto bolor pode ser obtida à luz da metafísica da Vontade? O que significa ser vivo dentro deste marco conceitual?

Para iniciar a responder esta pergunta é importante darmos um passo atrás e retomarmos o ponto de inflexão através do qual Schopenhauer passa do mundo como representação para o mundo como Vontade, uma vez que por meio desta passagem é estabelecido o princípio metafísico que, por assim dizer, lançará luz por sobre a totalidade dos fenômenos, incluindo a vida, que é o foco temático do presente trabalho. Textualmente, este ponto de inflexão é apresentado no segundo capítulo do primeiro tomo de $O$ Mundo, especialmente nos $§ 17, \S 18$ e $\S 19$. Curiosamente, o movimento argumentativo de Schopenhauer relembra alguns traços da fenomenologia da familiaridade cotidiana desdobrada por Heidegger em Ser e Tempo, uma vez que o conceito de mundo apresenta-se como central neste movimento.

Posto na forma de pergunta, o ponto de inflexão pode ser formulado nos seguintes termos: de que modo e em que medida é possível ultrapassar o mundo como representação e chegar à essência íntima e na significação daquilo que se apresenta como representação? O início da resposta de Schopenhauer lança-mão de uma estratégia contra-factual: se o sujeito fosse um mero sujeito de conhecimento, um anjo alado destituído de corpo, então não seria possível encontrar o ponto de inflexão e permaneceríamos enredados e restritos ao mundo como representação (SCHOPENHAUER, 2005, p. 156). Mas isso tudo não é assim, e a chave para avançar em direção à essência do mundo é dada pelo corpo, pois ele é experimentado de duas formas irredutíveis: mediatamente como representação à maneira de todas as demais, como corpo qualquer, e imediatamente como vontade, como o meu corpo com o qual se trava uma relação irredutível em primeira

8 Este é um ponto delicado e que precisa ser tomado cum grano salis, pois atribuir literalmente a Schopenhauer o reconhecimento de diferentes modos de ser implicaria em entrar em um terreno instável repleto de questões difíceis. Apenas a título de ilustração, basta mencionar a dificuldade de se atribuir (ou se justificar a atribuição de) algo assim como o reconhecimento da diferença ontológica por parte de Schopenhauer, uma vez que em última instância toda a existência remonta à Vontade. Por outro lado, enquanto formas dos diferentes graus de objetidade da Vontade, as Ideias assumem um estatuto ontologicamente diferenciado em relação às objetidades, isto é, aos fenômenos. O que se sugere nesta passagem é ler o reconhecimento da diferença fundamental entre orgânico e inorgânico com recursos conceituais da ontologia fundamental, e não atribuí-los a Schopenhauer. Agradeço pela observação do parecerista sobre este importante ponto. 
A vida à luz da ontologia fundamental e da metafísica da Vontade: uma aproximação hermenêutica
Dndo. Gabriel Henrique

Dietrich [UFSM]

pessoa. ${ }^{9}$ Dada a relação entre corpo e Vontade, e dada a relação que o sujeito tem com seu próprio corpo, é possível encontrar no corpo o ponto de inflexão que permite ultrapassar o mundo como representação e chegar ao mundo como Vontade, isto é, determinar o princípio metafísico enquanto tal, a significação do mundo qua representação (SCHOPENHAUER, 2005, p. 157). ${ }^{10}$

Uma vez determinado o corpo como objetidade da Vontade, Schopenhauer estende, sob pena de permanecer em um mistério absoluto e incompreensível, a Vontade como fundamento de todos os fenômenos. Ou seja, tudo aquilo que é representação também é Vontade, e, como tudo o mais, recebe desde o seu fundamento a sua significação. Neste ponto é importante destacar que mesmo que todos os fenômenos ou representações tenham seu enraizamento na Vontade, que é una e indivisível, eles não se confundem entre si no sentido de serem indiferenciáveis ou idênticos, amorfos, para usar uma expressão que logo a seguir será retomada. Muito ao contrário, como visto na citação anterior, considerados os âmbitos do orgânico e do inorgânico, por exemplo, há entre eles uma diferença fundamental. Mas em que consiste propriamente esta diferença? E em que medida ela é fundamental?

É bastante conhecido que Schopenhauer propõe uma interpretação das representações, fenômenos ou objetidades da Vontade em termos de graus de complexidade relativamente à Vontade, e que aos graus de objetidade da Vontade ele vincula as Ideias Platônicas (SCHOPENHAUER, 2005, p. 191). Este

9 Este é outro ponto de aproximação que se poderia estabelecer entre a fenomenologia de Heidegger e a Metafísica da Vontade, pois em ambas há uma relevância metodológica decisiva para o papel que a primeira pessoa desempenha no interior destes dois marcos conceituais: no primeiro caso como a condição do acesso e da tematização da compreensão de ser e, no segundo, como ponto de inflexão e justificação para a passagem do mundo como representação para o mundo como Vontade. Nesse sentido, considerando, por um lado, a importância metodológica decisiva que a primeira pessoa desempenha para a fenomenologia, e, por outro, aceitando que a descrição fenomenológica se dá em termos de correlação entre, por exemplo, ato de consciência e objeto intencional, para usar um vocabulário husserliano, ou entre compreensão de ser e modo de ser, para usar um vocabulário heideggeriano, talvez Schopenhauer pudesse ser lido, até certa medida, como um proto-fenomenólogo. Na medida em que a orientação deste texto consiste em um movimento hermenêutico aproximativo, a ênfase aqui recai sobre os elementos comuns de ambas as perspectivas, o que não significa que não seja possível também destacar múltiplas diferenças. Em verdade, um exercício hermenêutico mais inclusivo e satisfatório poderia ser feito justamente em ambas as direções: por um lado destacando pontos em comum e por outro lado destacando pontos de divergência. Ao final do texto serão colocadas algumas questões que abrem este horizonte de contraste no interior do qual é possível visualizar outras linhas de interpretação a se desdobrar em trabalhos ulteriores.

10 A aproximação entre as perspectivas em primeira pessoa e o papel que os conceitos de mundo e de corpo desempenham para cada um dos autores abre um vasto campo de problematizações que podem configurar o horizonte de outro exercício hermenêutico, este no qual se procuraria apresentar em detalhe as diferenças e especificidades aqui envolvidas. Dentre estas diferenças e especificidades, cabe mencionar às relativas ao possível compromisso com e à possível recusa do conceito de representação, que certamente acarreta toda sorte de consequências ontologicamente importantes. 
é um ponto obscuro da metafísica da Vontade que envolve uma série de dificuldades e complexidades, e não é possível aqui esgotar todas as sutilezas que estão em jogo. Para o horizonte deste trabalho, contudo, basta apenas destacar que Schopenhauer reconhece diversos graus de objetidade e que eles são tomados como Ideias à quais o sujeito tem acesso, pois apesar de haver alguma mudança e fluxo no âmbito das representações e dos fenômenos, também há permanência e estabilidade, isto é, há formas invariantes e que estruturam e delineiam formalmente o estofo cambiante dos fenômenos. Ou seja, não só a Vontade não se expressa de modo amorfo e sem contornos bem definidos, como estas formas possuem um status ontologicamente decisivo, porquanto correspondem aos diversos graus de objetidade por meio dos quais a Vontade fenomenaliza-se e pode chegar a ser representação. Como exemplos de graus de objetidade da Vontade, do menos para o mais complexo, são mencionadas as forças da natureza, como a gravidade, as plantas, os animais e o ser humano: cada exemplo destes diria respeito a um determinado grau de objetidade por meio do qual a Vontade irrompe no tempo e no espaço, individualizando-se qua fenômeno (SCHOPENHAUER, 2005, p. 192).

Tendo por base que a Vontade como princípio metafísico é caracterizada como um ímpeto cego e irresistível, as diferentes formas de suas expressões fenomênicas travam uma luta pela permanência. A luta e o conflito entre as objetidades da Vontade assume diversos contornos e significados, pois no caso do ser humano, o mais alto grau de objetidade, isso conduz para problemas da ordem da ética, para os quais a compaixão desempenha um papel fundamental (SCHOPENHAUER, 2005, p 212). Na medida em que o ser humano é parte da vida, um tratamento completo para o problema da vida à luz da metafísica da Vontade também incluiria uma reconstrução da ética schopenhaueriana, algo que não será feito aqui. Antes, o interesse aqui posto é sobre o fenômeno da vida em geral, e a discórdia da Vontade consigo mesma que se expressa na luta pela vida. O problema pode ser posto considerando dois lados da mesma moeda, por assim dizer: 1 . O caráter finito da matéria e 2. O caráter de complexidade almejado pela Vontade.

No que diz respeito ao caráter finito da matéria, ele conduz ao problema da luta, conflito e autodiscórdia da vida na medida em que diferentes formas ou objetidades da Vontade, ao se expressarem fenomenicamente, tomam para si a matéria que outra forma ou objetidade tomaria, o que implica na destruição desta forma menos complexa de expressão da Vontade (SCHOPENHAUER, 2005, 211). Isso conduz para o problema adicional dos graus de complexidade: na medida em que um grau mais complexo ou superior de objetidade se apresenta, ele 
A vida à luz da ontologia fundamental e da metafísica da Vontade: uma aproximação hermenêutica
Dndo. Gabriel Henrique

Dietrich [UFSM]

precisa submeter um grau mais baixo e dominá-1o ${ }^{11}$. Bem ao seu estilo, Schopenhauer fornece muitos exemplos que ilustram com vivacidade este conflito, por exemplo, em relação à alimentação, na qual uma determinada objetidade, por exemplo, um herbívoro como um coelho, para manter-se vivo, precisará aniquilar alguma planta e digerir seus nutrientes. Como a planta ela mesma é Vontade objetivada, haverá resistência e luta, por mais que, neste caso em especial, seja uma luta silenciosa e relativamente pacífica, dadas as características da planta e do coelho. Mas, avançando um pouco no exemplo, pense-se em um lobo, que para manter-se vivo precisará caçar o coelho. Obviamente, o coelho irá se esconder, esquivar e lutar ao máximo para que não seja destruído, enquanto que o lobo ficará à espreita para devorá-lo. Essa dinâmica do caçar do predador e do fugir da presa demarca bem o problema do conflito da Vontade consigo mesma, mas Schopenhauer destaca, na seguinte passagem de $O$ Mundo como Vontade e como Representação, um exemplo adicional que, segundo ele, é ainda mais expressivo:

O mais flagrante exemplo desse tipo de conflito é fornecido pela formiga bulldog-ant da Austrália: quando se a corta, tem início uma luta entre a cabeça e a cauda: a primeira ataca com mordidas a segunda, e esta se defende bravamente com o ferrão; a luta dura cerca de meia hora, até que ambas morrem ou são carregadas pelas outras formigas (p. 212).

Neste exemplo é possível destacar como a auto-discórdia fundamental da Vontade como um todo se expressa, por assim dizer, em um único indivíduo diminuto, uma simples formiga, que literalmente luta com todas as suas armas mesmo que esteja divida em duas. Na medida em que ela luta, por assim dizer, contra si mesma, mas apenas a partir do momento em que ela é dividida e perde unidade, este conflito demarca bem a luta pela vida em termos do princípio de individuação: diferentes indivíduos situados em diferentes pontos do tempo e do espaço travam entre si uma luta incessante para a permanência no tempo e no espaço.

11 Como a Vontade não se expressa qua objetidade apenas nas mais variadas formas de viventes, mas abarca o que quer que seja fenômeno, este conflito se estende também para as formas inorgânicas de objetidade, como as forças da natureza e as relações químicas entre minerais. Considerando a relação entre orgânico e inorgânico, é possível formular, respectivamente, o conflito em termos de uma luta pela manutenção da forma, o que implica destruir e modificar a matéria, ou uma luta pela manutenção da matéria, o que implica em modificar ou assumir variadas formas (SORIA, 2012). 
A vida à luz da ontologia fundamental e da metafísica da Vontade: uma aproximação hermenêutica
Dndo. Gabriel Henrique

Dietrich [UFSM]

Considerando os resultados da hermenêutica ontológica da vida, seria possível interpretar este exemplo de Schopenhauer à luz da vida entendida como organismo qua órgão, aptidão, pulsão, aprisionamento e círculo envoltório. A relação de anterioridade entre aptidão e órgão parece ser corroborada neste exemplo, uma vez que o ser-apto do ferrão e das pinças é lançado um contra o outro, mesmo que momentos antes tenham pertencido a um mesmo indivíduo, a serviço do mesmo organismo. ${ }^{12}$ Do mesmo modo, a pulsão e o aprisionamento também parecem se destacar aqui, uma vez que o ser-apto do órgão, no caso da pinça e do ferrão, é disparado assim que um é posto diante do outro. Por fim, neste exemplo o círculo envoltório poderia ser interpretado como tendo sido rompido ou até mesmo multiplicado, de modo que cada uma das duas partes da formiga trouxe consigo o seu círculo pela manutenção do qual suas respectivas partes, isto é, a aptidão de seus órgãos (ferrão e pinças), foi posta em movimento.

Ao fim da passagem constam duas possibilidades: ou a morte da formiga ou seu arrastar pelas outras. De qualquer maneira, a passagem indica a dinâmica e movimento da vida, que consiste na alternância de forças e conflito. Apesar de talvez inicialmente parecer um fato banal e sem importância, faz parte desta dinâmica o morrer. Mas considerando a passagem anterior, esta dinâmica abre, por assim dizer, um abismo, pois se há uma diferença fundamental entre o orgânico e o inorgânico, e se, em algum momento, todo orgânico eventualmente chega a perecer, então de alguma maneira todo orgânico ao fim e ao cabo acaba retornando ao inorgânico. Esta seria uma dinâmica surpreendente, enigmática, uma vez que dois âmbitos em princípio absolutamente distintos acabam, em um determinado momento, por se identificar. No exemplo da formiga, sejam suas partes carregadas por outras ou deixadas a morrer ali mesmo, em pouco tempo a decomposição começará, e então a sua figura, sua forma e aparência, deixará lugar para um vazio, embora seus elementos materiais sejam transformados, por exemplo, em nutrientes para o solo (ou para algum animal que eventualmente a devoraria). De que maneira então é possível lançar luz para esta dinâmica enigmática?

12 É importante destacar aqui a importância da dimensão modal do modo de ser da vida, conforme reconhecida por Heidegger. Em linhas gerais, este reconhecimento radica na identificação de que a determinação ontológica da vida é obtida a partir do conceito modal de possibilidade orgânica. Uma consequência ontologicamente importante disto seria a de que, à luz do programa da ontologia fundamental, organismos não são entes prontos e acabados, fechados em si mesmos, mas abertos e dinamicamente flexíveis. Mais especificamente, esta dinâmica e flexibilidade abrem o horizonte para se considerar outro traço ontologicamente decisivo da vida, a saber, a sua mobilidade interna específica que contém nascimento, crescimento, maturação, hereditariedade e morte. Nesse sentido, Heidegger reconhece que a tarefa de elaborar uma hermenêutica ontológica da vida significa também colocar o problema da morte. Na medida em que o conceito de possibilidade recebe em Heidegger uma qualificação relativa e respectiva a modos de ser específicos, este seria um ponto de contato crítico com Schopenhauer, a saber, analisar em que medida o modo como a vida é conceitualizada à luz da metafísica da Vontade também lança-mão do conceito de possibilidade, e, adicionalmente, em que medida este conceito seria consistente com o conceito orgânico de possibilidade. 
Desde a perspectiva da metafísica da Vontade, por mais que os graus mais altos de objetidade acabem por submeter os mais baixos, a tendência é que esta vitória seja apenas parcial e por tempo determinado, uma vez que a Vontade atua ininterruptamente e com variações mínimas nos graus mais baixos. Um exemplo curioso desta dinâmica entre o orgânico e o inorgânico, e que está, por assim dizer, a meio caminho do morrer, é o sono e o cansaço que resultam da alimentação: eles são resultados da luta travada entre aquilo que serviu de alimento e o sistema digestivo do organismo que ingeriu alimento. Tudo isto nos dá uma imagem da vida, expressão da Vontade, como luta e conflito, um incessante combate pela preservação em meio à dinâmica complexa da mudança orgânica. Uma consequência ontologicamente importante disto é a de que o modo de ser da vida, que por assim dizer é aberto e volátil, impede uma elucidação completa e total, principalmente se esta elucidação for entendida em termos de uma descrição físico-matemática na qual são destacadas suas propriedades objetivas mensuráveis, pois isso implicaria compreender a vida em termos de estabilidade, fixidez e imobilidade. Em última instância isto significa que por sobre a agitação e dinâmica da vida, com seu violento movimento entre o nascer e o morrer, paira um mistério, uma indeterminação essencial, que paradoxalmente talvez pudesse ser formulado nos termos de que a essência da vida impede que sua essência seja tematizada em sua integralidade. Seja interpretada como um determinado modo de ser e à luz dos conceitos do programa da ontologia fundamental, seja interpretada à luz dos conceitos da metafísica da Vontade, a vida, esta possibilidade de ser que se configura e reconfigura dinamicamente em exuberante agitação, seria sempre também mistério, porquanto não completa e sempre em emergência, desdobrando-se no enigma da dinâmica do ser e do não-ser.

\section{Considerações finais}

A aproximação hermenêutica ensaiada aqui não possui um caráter de rigor exegético no sentido de procurar uma completude ou uma orientação sistemática. Para isto seria exigido muito mais, que fossem considerados outros textos, cotejadas interpretações sob diversas perspectivas e procurado uma unidade ampla e linear. Por outro lado, dado o caráter hermenêutico da aproximação, há um traço de circularidade e complementaridade conceitual: a tarefa da ontologia fundamental de colocar a pergunta pela essência da vida seria complementada pelo modo como a vida é interpretada à luz da metafísica da Vontade, assim como ao revés. O resultado parcial deste movimento interpretativo 
circular seria uma ampliação, complexificação e sofisticação do modo como o problema da essência da vida viria à tona, especialmente em razão de faltar, na hermenêutica ontológica da vida, considerações positivas sobre a essência da vida qua plantas, isto é, da vida em sua forma vegetativa, que é elucidada por Schopenhauer em termos da metafísica da Vontade. Adicionalmente, considerando outro sentido de direção da circularidade hermenêutica, abre-se também a possibilidade de se estabelecer um movimento aproximativo de múltipla orientação, incluindo não apenas aproximações, mas também contrastes e diferenciações importantes entre as duas interpretações da vida. Esta possibilidade alternativa pode ser posta inicialmente em termos de dois problemas principais que reúnem em seu interior um conjunto de questões.

$\mathrm{O}$ primeiro destes problemas diz respeito à postura crítica de Heidegger em relação ao par conceitual sujeito/objeto. Esta postura é bastante conhecida e resultou em importantes contribuições da fenomenologia hermenêutica para vários tópicos da filosofia contemporânea. Deixando de lado as sutilezas por detrás desta atitude, em última instância a justificativa de Heidegger para rejeitar este par conceitual decorre da situação hermenêutica da qual ele emerge: trata-se de um ponto de partida marcadamente epistêmico, e que acarretaria uma série de consequências problemáticas. Se a situação hermenêutica a partir da qual emerge a metafísica da Vontade pode ser considerada nos termos de uma situação delineada essencialmente por traços epistêmicos expressos no par conceitual sujeito/objeto, permanece em aberto. Formulado interrogativamente: de que maneira a clássica crítica de Heidegger ao par sujeito objeto pode ser estendido e atingir o modo como Schopenhauer pretende lançar luz sobre a vida? Quais implicações ontológicas do compromisso com este par conceitual? Admitindo um compromisso da metafísica da Vontade com uma compreensão tradicional de ser, em que medida seria possível reter contribuições desta mesma metafísica para o modo de ser da vida?

O segundo dos problemas diz respeito à relação entre mundo e natureza. Mais especificamente, o problema diz respeito à direção ou ao impulso desta relação: é o mundo que deve ser interpretado à luz da natureza ou, ao contrário, é a natureza que deve ser interpretada a partir do mundo? As consequências da adoção de certo direcionamento são ontologicamente importantes, e cada uma delas envolve dificuldades particulares. A orientação interpretativa assumida em Ser e Tempo vai do mundo em direção à natureza, e no curso Os Conceitos Fundamentais da Metafisica, ela se expressa por meio das três teses diretivas. Por outro lado, uma vez que a Vontade é tomada como um princípio metafísico, Schopenhauer parece percorrer a direção contrária e interpretar o mundo à 
luz da Vontade. Obviamente, um cuidado inicial seria o de considerar em que medida e até que ponto natureza seria identificável com Vontade, e, assim, em que medida a interpretação de Schopenhauer iria da natureza para o mundo. Nesse sentido, outras das perguntas que ficam em aberto e que poderiam ser desdobradas em um esforço de aproximação hermenêutica alternativa e complementar a esta ensaiada são as seguintes: de que maneira estes dois impulsos e direcionamentos destas duas orientações interpretativas são articuláveis entre si? Seria possível interpretar tanto o mundo à luz da natureza quanto a natureza à luz do mundo? E o que dizer do papel ontológico decisivo do tempo: em que medida a metafísica da Vontade está comprometida inadvertidamente de saída com um conceito específico de tempo a partir do qual a vida é interpretada?

\section{Recebido em: 15.05.2019 | Aprovado em: 29.10.2019}

CARMAN, T. Heidegger's Concept of Presence, Inquiri: an interdisciplinar journal of philosophy. New York, NY, vol. 38:4, p.432-453, 1995.

CROWELL, S. Heidegger's Phenomenological Decade. Man and World. Printed in Netherlands, vol. 28, pp. 435-448. 1995.

McDANIEL, K. The Fragmentation of Being, United Kingdom, Oxford. 2017.

McNEILL, W. Life Beyond Organism: Animal Being in Heidegger's Freiburg Lessons,1929-30. In: P. STREEVES, Animal Others: On Ethics, Ontology, and Animal Life. Albany, SUNY Press, 1999.

MOREIRA, F. Sobre a Relação entre Vida e Vontade na Metafísica da Natureza de Schopenhauer. Voluntas: Estudos sobre Schopenhauer. Santa Maria, BR, vol. 2, pp. 44-62, 2011.
HEIDEGGER, M. Ser y Tiempo: Ed: Trotta. Madrid. 2009

HEIDEGGER, M. Os Conceitos Fundamentais da Metafísica: Mundo, Finitude e Solidão. Rio de Janeiro. Ed. Forense Universitária. 2011.

REIS, R. R. Aspectos da Modalidade. Rio de Janeiro. Ed: Via Verita. 2014.

SANTOS, A. Orgânico e Inorgânico em "Sobre a Vontade na Natureza". Voluntas: estudos sobre Schopenhauer. Santa Maria, Br, vol. 3, pp. 195-202. 2012.

SCHOPENHAUER, A. O Mundo como Vontade e como Representação. São Paulo, Ed: Unesp. 2005.

SILVEIRA, A. 2013. A Relação Ontológica entre Vida e Existência na Fenomenologia Her- 
menêutica de Martin Heidegger. Santa Maria. 135 páginas. UFSM. 2013. Dissertação de mestrado em filosofia. Acessível em: http://w3.ufsm.br/ ppgf/wp-content/uploads/2011/10/Disserta\%C3\%A7\%C3\%A3o-Andr\%C3\%A9_Final.pdf

ZÖLLER, G. Schopenhauer and the Problem of Metaphysics. Man and World. Vol. 28. Pp 1-10, Printed in Netherlands 1995.

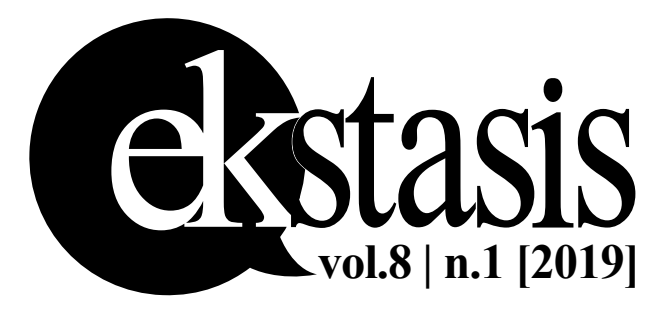

